OPEN ACCESS

Edited by:

Paul De Vos,

University Medical Center

Groningen, Netherlands

Reviewed by:

Mourad Aribi,

University of Tlemcen, Algeria

Christopher Alan Jolly,

University of Texas at Austin,

United States

*Correspondence:

Maha Abdullah

maha@upm.edu.my

Specialty section:

This article was submitted to

Nutritional Immunology,

a section of the journal

Frontiers in Immunology

Received: 04 April 2017 Accepted: 24 May 2017

Published: 09 June 2017

Citation:

Jumat NR, Chong MY, Seman Z,

Jamaluddin $R$, Wong NK and Abdullah M (2017) Sexual Dimorphic

Responses in Lymphocytes of

Healthy Individuals after Carica

papaya Consumption.

Front. Immunol. 8:680.

doi: 10.3389/fimmu.2017.00680

\section{Sexual Dimorphic Responses in Lymphocytes of Healthy Individuals after Carica papaya Consumption}

\author{
Nur Ramziahrazanah Jumat ${ }^{1}$, Mun Yee Chong ${ }^{1}$, Zainina Seman ${ }^{2}$, Rosita Jamaluddin ${ }^{3}$, \\ Nyet Kui Wong ${ }^{4}$ and Maha Abdullah ${ }^{1 *}$
}

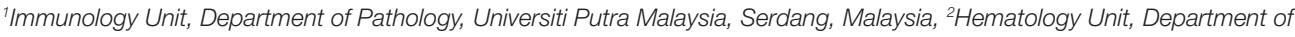
Pathology, Universiti Putra Malaysia, Serdang, Malaysia, ${ }^{3}$ Department of Dietetics and Nutrition, Faculty of Medicine and Health Sciences, Universiti Putra Malaysia, Serdang, Malaysia, ${ }^{4}$ Biotechnology Program, Faculty of Science and Natural Resources, Universiti Malaysia Sabah, Kota Kinabalu, Malaysia

Sexual dimorphism in immune response is widely recognized, but few human studies have observed this distinction. Food with endo-immunomodulatory potential may reveal novel sex-biased in vivo interactions. Immunomodulatory effects of Carica papaya were compared between healthy male and female individuals. Volunteers were given fixed meals supplemented with papaya for 2 days. Changes in blood immune profiles and hormone levels were determined. In females, total natural killer (NK) cell percentages decreased $(12.7 \pm 4.4$ vs $14.6 \pm 5.8 \%, p=0.018, n=18)$ while $B$ cells increased $(15.2 \pm 5.5$ vs $14.5 \pm 5.0, p=0.037, n=18)$ after papaya consumption. Increased $17 \beta$-estradiol (511.1 \pm 579.7 vs $282.7 \pm 165.0 \mathrm{pmol} / \mathrm{l}, p=0.036, n=9$ ) observed in females may be crucial to this change. Differentiation markers (CD45RA, CD69, CD25) analyzed on lymphocytes showed naïve (CD45RA+) non-CD4+ lymphocytes were reduced in females $(40.7 \pm 8.1$ vs $46.8 \pm 5.4 \%, p=0.012, n=8)$ but not males. $A$ general suppressive effect of papaya on CD69+ cells, and higher percentage of CD69+ populations in females and non-CD4 lymphocytes, may be relevant. CD107a ${ }^{+}$NK cells were significantly increased in males (16.8 \pm 7.0 vs $14.7 \pm 4.8, p=0.038, n=9)$ but not females. Effect in females may be disrupted by the action of progesterone, which was significantly correlated with this population $(R=0.771, p=0.025, n=8)$ after papaya consumption. In males, total T helper cells were increased $(33.4 \pm 6.4$ vs $32.4 \pm 6.1 \%$, $p=0.040, n=15)$. Strong significant negative correlation between testosterone and CD25 ${ }^{+} \mathrm{CD} 4^{+}$lymphocytes, may play a role in the lower total $C D 4^{+} \mathrm{T}$ cells reported in males. Thus, dissimilar immune profiles were elicited in the sexes after papaya consumption and may have sex hormone influence.

\section{Keywords: natural killer cells, T cells, CD25, CD69, CD107a, sex hormones, Carica papaya}

\section{INTRODUCTION}

Sexual dimorphism in immune response of the innate and adaptive systems has been extensively reviewed in literature and manifested in differential resistance to infections. Females in general are better than males in defense against a variety of bacterial, viral, and parasitic infestations $(1,2)$. Dimorphism in severity and pathogenesis are also apparent as certain infectious and parasitic diseases increase mortality in females but not males (3). Sex hormones and sex chromosome-related 
genes such as toll-like receptors, cytokine receptors involved in $\mathrm{T}$-cell and B-cell activity in the $\mathrm{X}$ chromosome and inflammatory pathway genes in the $\mathrm{Y}$ chromosome $(4,5)$ are expected to be major contributors to this disparity.

Sex differences in non-communicable diseases are also observed in particular autoimmune diseases (6) as well as metabolic diseases, hypertension, cardiovascular diseases, psychiatric, neurological disorders, and cancer (7). More than $80 \%$ of all patients with autoimmune disease are women. Sex as a risk factor in coronary artery disease is observed in incidence rate and also age of onset, progression, treatment efficacy, morbidity, and mortality (8). These dissimilarities are attributed to genetic as well as hormonal differences and interactions and responses to environmental factors including infection, diet, drugs, stress, as well as behavior. Host hormone interactions with commensal gut microbiome are suggested to shape the microbiome composition (9), which is essential in immune homeostasis. Thus, sex matters and must be a consideration when decisions around therapeutic intervention strategies are being developed (9). Substantial data have accumulated from many epidemiological studies. In vitro studies demonstrating effects of sex hormones on immune cell subsets are well documented. However, in vivo human studies are still lacking.

Immunomodulatory potentials of phytochemicals and purified components of natural products are well studied. Whole food and its nutrients also have immunomodulatory effects, health healing potential, and play a role in homeostatic maintenance of the immune system but are less investigated. Grape juice consumption mobilized gamma-delta $\mathrm{T}$ cells and maintained immunity in healthy humans (10). A study on mice showed ginseng berry extract injected into mice exerted immunostimulatory effect by increasing pro-inflammatory molecules in dendritic cells from spleen after $24 \mathrm{~h}$ treatment (11). In diseased models, polysacccharide fractions from Momorica charantia, an edible medicinal vegetable, significantly increased various immune indexes to normal control levels in cyclophosphamide-induce immunosuppressed mice (12). Feijoa sellowiana Berg var. coolidge fruit juice consumption was shown to have anti-inflammatory activity on edema-induced mice within first hour of treatment (13) while agipenin, a natural flavonoid reduced neuroinflammation by protection against damage from dendritic cells stimulated T cells in experimental autoimmune encephlalomyelitis mouse models (14). Dietary polyphenols were found to exert a regulatory role on dendritic cell function. Researches in human are few and still new but represent an area of scientific need, opportunity, and challenge (15).

Carica papaya fruit is commonly consumed worldwide. It has high antioxidant activity (16) and rich in phytochemicals such as flavonoids (17). Different plant parts such as fruit, leaf, seed, root, bark, and flowers have been used as health treatments in tropical countries where it is grown. The seeds of papaya, however, have contraceptive effect on male fertility as well as manifest antifertility, anti-implantation, and abortifacient activity in female rats (18) suggesting a possibility to alter sex hormone levels.

We examined the potential of papaya fruit to modulate immune profiles and sex hormones in healthy male and female individuals. We observed differential immune profiles in sexes after papaya consumption, which may be influenced by sex hormones.

\section{METHODOLOGY}

\section{Subjects}

Apparently healthy individuals, age 18-35 years old, with no history of chronic or acute illness, no recent history of vaccination, piercing or blood transfusion, and not on medication or supplements were included. A total of 33 subjects, 15 males and 18 females, were recruited and underwent a papaya supplementation experiment. Subsequent lab investigations, however, were not conducted on all samples collected. Female subjects were enlisted during their second or third week after onset of menstruation and determined not on oral contraceptive. This study was approved by the Medical Research Ethics Committee, Faculty of Medicine and Health Sciences, Universiti Putra Malaysia. All procedures complied with the principles of the Declaration of Helsinki. Informed written consents were obtained from participants.

\section{Papaya Supplementation Experimental Design}

A 5-day experiment was designed. Two subjects, one male and one female, were randomly selected at a time. Food intake was controlled with provision of standard meals consisting of bread/ rice/noodle, chicken, vegetables, and liquid. The menu for day 3 and day 4 were replicates of day 1 and day 2, respectively. A pre-exposure period of 2 days (without papaya) was followed by 2 days with $100 \mathrm{~g}$ of fresh papaya fruit (fruit color index 4) in the day's three major meals. Daily dietary recall was conducted to confirm that the fruit provided each time was completely consumed while a medical call was carried out to determine no adverse effects. A peripheral blood sample $(20 \mathrm{ml})$ was collected in $\mathrm{K}_{2}$ EDTA vacutainers in the morning before meal of day 3 $(0 \mathrm{~h})$ and day $5(48 \mathrm{~h})$. Either whole blood or peripheral blood mononuclear cells (PBMCs) was used in the experiments. Whole blood was used directly after withdrawal. PBMC was isolated by density centrifugation with Ficoll-Paque (GE Healthcare, USA) and stored over liquid nitrogen until further use. Plasma was collected and stored at $-80^{\circ} \mathrm{C}$ for measurement of sex hormones levels.

\section{Lymphocyte Subset Enumeration}

Percentages and absolute counts of lymphocyte subsets in whole blood were determined with the BD Multitest ${ }^{\mathrm{TM}}$ IMK kit (BD Biosciences, USA) containing antibodies against CD45, CD3, CD4, CD8, and $\mathrm{CD} 16^{+} \mathrm{CD} 56$ together with BD Trucount tubes, according to procedures provided by manufacturer. All samples were tested. Cells were acquired on a BD FACSCanto flow cytometer (BD) and analyzed with FACSCanto Clinical Software (BD).

\section{Expression of CD45RA, CD69, and CD25 on CD4 ${ }^{+}$T Cells and Non-CD4 ${ }^{+}$ Lymphocytes}

From here on, only nine paired samples from males and nine paired samples from females were tested. Subsequent missing samples were due to loss of data during a transition period. For surface marker studies, heparinized whole blood sample $(100 \mu \mathrm{l})$ was incubated with monoclonal antibodies to CD4-PerCP, 
CD45RA-FITC, CD25-APC, and CD69-PE purchased from Becton Dickinson (USA), following standard procedures. Briefly, after 20 min incubation in dark at $4^{\circ} \mathrm{C}$, red blood cells were lysed with $1 \times$ lysing solution (Becton Dickinson, USA). After washing with $1 \times$ PBS, cells were re-suspended in $500 \mu$ of $2 \%$ paraformaldehyde. Ten thousand events gated on $\mathrm{CD}^{+}$bright population were acquired on a flow cytometer (BD LSR-Fortessa) and analyzed using FACSDiva (Becton Dickinson, USA).

\section{Surface Marker Expression of Interleukin (IL) Receptors (IL-12Rß2, IL-15R $\alpha$, IL-21R) on CD8 ${ }^{+} \mathrm{T}$ and NK Cells}

Whole blood $(600 \mu \mathrm{l})$ diluted with equal volume of RPMI 1640 medium without FBS was dispensed in BD Falcon polystrene tubes and incubated with $400 \mathrm{ng} / \mathrm{ml}$ phorbol myristate acetate (PMA) (Sigma-Aldrich, USA) together with calcium ionophore (Sigma-Aldrich, USA) and golgi stop containing monensin (Becton Dickinson, USA) for $6 \mathrm{~h}$ at $37^{\circ} \mathrm{C}$ and $5 \% \mathrm{CO}_{2}$. After incubation, four-color staining (FITC/PE/APC/PerCP) for lineage markers, CD3, CD8, and CD56 and one of the surface IL receptor, IL-12R $\beta 2$-PE, IL-15R $\alpha$-PerCP, or IL-21R-PE was performed. Subsequently, RBC was lysed with $1 \times$ lysing solution (Becton Dickinson, USA) following manufacturer's protocol and then fixed with $2 \%$ paraformaldehyde before analysis using $\mathrm{BD}$ FACSDiva software on LSR-Fortessa flow cytometer (BD).

\section{Intracellular Cytokine Staining for Interferon- $\gamma$ (IFN- $\gamma$ )}

The same stimulation procedure as above (cytokine receptors) was carried out. After $6 \mathrm{~h}$ incubation, cell surface staining for lineage specific markers (CD3, CD8, CD56) was performed. To detect IFN- $\gamma$ secretion, cells were fixed with $2 \%$ paraformaldehyde followed by permeabilization with BD Perm/Wash solution before staining for intracellular IFN- $\gamma$ PE-labeled antibody. Cells were analyzed on BD LSR-Fortessa flow cytometer (BD).

\section{CD107a Degranulation Assay on $\mathrm{CD}^{+} \mathrm{T}$ and NK Cells}

Peripheral blood mononuclear cell $\left(1 \times 10^{6}\right.$ cells $\left./ \mathrm{ml}\right)$ from volunteers were re-suspended in $500 \mu$ l of complete RPMI 1640 medium in BD Falcon polystrene tubes and incubated with $100 \mathrm{ng} / \mathrm{ml}$ PMA with calcium ionophore and golgi stop-containing monensin. PBMC was also incubated with monoclonal antibody to CD107a. Tubes were vortexed gently and incubated for $5 \mathrm{~h}$ in dark at $37^{\circ} \mathrm{C}$ with $5 \% \mathrm{CO}_{2}$. Subsequently, cells were washed with PBS, stained with monoclonal antibodies specific for CD3, CD8, and CD56 and analyzed on BD LSR-Fortessa flow cytometer (BD, USA).

\section{Sex Hormone Assay}

Measurement of sex hormone levels was outsourced to a local pathology laboratory for detection of $17 \beta$-estradiol, progesterone, and testosterone serum levels using System ARCHITECT ci8200 together with respective kits. Normal ranges were provided with the kits. Levels of sex hormones (17 $\beta$-estradiol, progesterone, and testosterone) were then correlated with immune profiles determined in the study.

\section{Statistical Analysis}

The Shapiro-Wilk and Kolmogorov-Sminov tests showed nonnormal distribution of the data collected here; therefore, nonparametric Wilcoxon matched pair test was used to compare paired groups and Spearman's correlation test was performed to determine associations from changes in variables that occurred after papaya consumption. Statistical analysis was performed using SPSS (version 22.0). $p<0.05$ was considered significant. Results were presented as mean $\pm \mathrm{SD}$.

\section{RESULTS}

\section{Only NK Cells and a CD69+ Subpopulation Were Significantly Different between the Sexes}

Comparison between males and females for all parameters combined for the two time points showed significantly lower percentages of total CD3-CD56/16 ${ }^{+}$NK cells in females. Interestingly, a non-CD4 lymphocyte subpopulation with activated features $\left(\mathrm{CD} 45 \mathrm{RA}^{-} \mathrm{CD}^{2} 9^{+} \mathrm{CD} 25^{-}\right)$was significantly higher $(10.4 \pm 9.4$ vs $5.3 \pm 2.3, p=0.032, n=32$ ) in females compared to males. As expected, the sex hormones levels were significantly different between males and females (Table 1).

\section{$17 \beta$-Estradiol and Progesterone Levels Were Significantly Increased in Females after Papaya Consumption}

Plasma sex hormone levels of $17 \beta$-estradiol ( $p=0.036, n=9)$ and progesterone $(p=0.039, n=9)$ were significantly increased in females after papaya consumption (Figure 1; Table 1). Even though the experiment was designed to be carried out during the follicular phase of the female menstrual cycle, two subjects showed luteal phase levels for progesterone. These samples were not excluded as this study analyzed pre- and post-levels. None of the hormones tested demonstrated significant change in males after C. papaya consumption.

\section{Total NK Cell Percentages Were Significantly Reduced in Females while Total CD4 ${ }^{+}$T Cell and Total B Cell Were Significantly Increased in Males and Females, Respectively, after Papaya Consumption}

Total NK cells from peripheral blood were significantly downregulated ( $p=0.018, n=18$ ), while total B cell percentages were significantly increased $(p=0.037, n=18)$ in females after papaya consumption (Figure 2). Total $\mathrm{CD}^{+} \mathrm{T}$ cells was significantly increased $(p=0.040, n=15)$ in males (Table 1).

A negative association was detected between change in $17 \beta$-estradiol levels and change in NK cell percentages in females $(R=-0.586, p=0.097, n=9)$ suggesting increased $17 \beta$-estradiol may play a role in downregulating NK cells. No significant 
TABLE 1 | Mean \pm SD values of sex hormones and immune parameters in healthy males and females, combined (all samples) and pre- and post-papaya consumption.

Pre-papaya vs post-papaya

\begin{tabular}{|c|c|c|c|c|c|c|c|c|c|c|c|c|c|c|c|c|c|}
\hline & \multicolumn{5}{|c|}{ All samples } & \multicolumn{3}{|c|}{ All subjects } & \multicolumn{3}{|c|}{ Male } & \multicolumn{3}{|c|}{ Female } & \multirow{2}{*}{\multicolumn{2}{|c|}{$\begin{array}{lc}\text { All } & \text { M } \\
& \text { (Pre- vs Post-) }\end{array}$}} & \multirow[t]{2}{*}{$\mathbf{F}$} \\
\hline & Male & $n$ & Female & $n$ & M vs $\mathrm{F}$ & Pre- & Post- & $n$ & Pre- & Post- & $n$ & Pre- & Post- & $n$ & & & \\
\hline \multicolumn{18}{|l|}{ Sex hormone } \\
\hline Estradiol (pmol//) & $98.1 \pm 26.5$ & 18 & $396.9 \pm 429.9$ & 18 & $P=0.000$ & $191.5 \pm 147.9$ & $303.5 \pm 451.9$ & 18 & $100.3 \pm 23.9$ & $95.8 \pm 30.1$ & 9 & $282.7 \pm 165.0$ & $511.1 \pm 579.7$ & 9 & $p=0.107$ & $p=0.594$ & $p=0.036$ \\
\hline Progesterone (nmol/l) & $0.3 \pm 0.0$ & 18 & $6.4 \pm 9.7$ & 18 & $p=0.010$ & $2.8 \pm 6.8$ & $4.0 \pm 8.1$ & 18 & $0.3 \pm 0.0$ & $0.3 \pm 0.0$ & 9 & $5.2 \pm 9.2$ & $7.61 \pm 0.5$ & 9 & $p=0.039$ & $p=1.000$ & $p=0.039$ \\
\hline Testosterone (nmo//) & $7.5 \pm 2.5$ & 18 & $0.8 \pm 0.5$ & 18 & $p=0.000$ & $4.3 \pm 4.0$ & $4.0 \pm 3.8$ & 18 & $7.8 \pm 2.5$ & $7.2 \pm 2.7$ & 9 & $0.8 \pm 0.4$ & $0.8 \pm 0.7$ & 9 & $p=0.248$ & $p=0.129$ & $p=1.000$ \\
\hline \multicolumn{18}{|c|}{ Lymphocyte subpopulation } \\
\hline $\mathrm{CD}^{+}{ }^{+} \mathrm{CD} 4^{+} \%$ & $32.9 \pm 6.1$ & 30 & $37.1 \pm 8.9$ & 36 & $p=0.056$ & $34.8 \pm 8.3$ & $35.6 \pm 7.8$ & 33 & $32.4 \pm 6.1$ & $33.4 \pm 6.4$ & 15 & $36.8 \pm 9.4$ & $37.5 \pm 8.5$ & 18 & $p=0.009$ & $p=0.040$ & $p=0.107$ \\
\hline $\mathrm{CD}^{+} \mathrm{CD}^{+}{ }^{+} \mathrm{cnt}$ & $858.5 \pm 264.2$ & 30 & $980.1 \pm 543.2$ & 36 & $p=0.643$ & $927.6 \pm 485.2$ & $922.0 \pm 397.6$ & 33 & $857 \pm 254.6$ & $860.0 \pm 282.5$ & 15 & $986.4 \pm 617.8$ & $973.7 \pm 475.0$ & 18 & $p=0.688$ & $p=0.910$ & $p=0.647$ \\
\hline $\mathrm{CD}^{+}{ }^{+} \mathrm{CD} 8^{+} \%$ & $28.1 \pm 9.1$ & 30 & $28.7 \pm 6.7$ & 36 & $p=0.610$ & $28.4 \pm 8.0$ & $28.5 \pm 7.7$ & 33 & $28.3 \pm 9.3$ & $28.0 \pm 9.1$ & 15 & $28.5 \pm 7.0$ & $29.0 \pm 6.6$ & 18 & $p=0.712$ & $p=0.694$ & $p=0.217$ \\
\hline $\mathrm{CD}^{+}{ }^{+} \mathrm{CD} 8^{+} \mathrm{cnt}$ & $748.4 \pm 352.0$ & 30 & $719.0 \pm 295.1$ & 36 & $p=0.872$ & $741.2 \pm 345.0$ & $723.6 \pm 297.9$ & 33 & $766.8 \pm 372.7$ & $730.1 \pm 342.0$ & 15 & $719.8 \pm 329.6$ & $718.2 \pm 265.8$ & 18 & $p=0.761$ & $p=0.551$ & $p=0.327$ \\
\hline $\mathrm{CD}^{-}{ }^{-} \mathrm{CD} 16^{+} 56 \%$ & $16.8 \pm 5.9$ & 30 & $13.6 \pm 5.2$ & 36 & $p=0.031$ & $15.7 \pm 6.0$ & $14.4 \pm 5.5$ & 33 & $17.1 \pm 6.0$ & $16.4 \pm 6.1$ & 15 & $14.6 \pm 5.8$ & $12.7 \pm 4.4$ & 18 & $p=0.010$ & $p=0.233$ & $p=0.018$ \\
\hline $\mathrm{CD}^{-}{ }^{-} \mathrm{CD} 16^{+} 56 \mathrm{cnt}$ & $465.3 \pm 274.9$ & 30 & $343.5 \pm 202.5$ & 36 & $p=0.053$ & $413.2 \pm 245.1$ & $384.5 \pm 245.9$ & 33 & $474.6 \pm 264.9$ & $456.1 \pm 293.5$ & 15 & $362.1 \pm 221.7$ & $324.8 \pm 185.9$ & 18 & $p=0.183$ & $p=0.650$ & $p=0.157$ \\
\hline CD3-CD19+ \% & $13.6 \pm 3.5$ & 30 & $14.9 \pm 5.2$ & 36 & $p=0.728$ & $14.1 \pm 4.4$ & $14.4 \pm 4.7$ & 33 & $13.7 \pm 3.8$ & $13.5 \pm 3.4$ & 15 & $14.5 \pm 5.0$ & $15.2 \pm 5.5$ & 18 & $p=0.216$ & $p=0.368$ & $p=0.037$ \\
\hline$C D 3^{-} \mathrm{CD} 19^{+} \mathrm{cnt}$ & $362.8 \pm 151.7$ & 30 & $373.1 \pm 199.3$ & 36 & $p=0.880$ & $370.0 \pm 194.3$ & $366.8 \pm 163.1$ & 33 & $371.4 \pm 153.7$ & $354.2 \pm 154.7$ & 15 & $368.9 \pm 227.1$ & $377.4 \pm 173.6$ & 18 & $p=0.531$ & $p=0.460$ & $p=0.149$ \\
\hline \multicolumn{18}{|c|}{ Expression of differentiation markers in lymphocyte subpopulations } \\
\hline \multicolumn{18}{|c|}{ CD4+ helper T cells } \\
\hline $\mathrm{CD} 4^{+} \mathrm{CD}_{45 \mathrm{RA}^{+}}$ & $14.3 \pm 4.3$ & 16 & $16.2 \pm 6.4$ & 16 & $p=0.515$ & $15.6 \pm 5.4$ & $15.0 \pm 5.7$ & 16 & $14.9 \pm 5.1$ & $13.8 \pm 3.5$ & 8 & $16.3 \pm 5.8$ & $16.2 \pm 7.4$ & 8 & $p=0.277$ & $p=0.161$ & $p=0.889$ \\
\hline CD69-CD25- & $52.5 \pm 12.6$ & 16 & $53.1 \pm 12.5$ & 16 & $p=0.838$ & $52.5 \pm 11.8$ & $53.1 \pm 13.3$ & 16 & $51.6 \pm 11.9$ & $53.5 \pm 14.0$ & 8 & $53.4 \pm 12.3$ & $52.7 \pm 13.4$ & 8 & $p=0.535$ & $p=0.263$ & $p=0.779$ \\
\hline $\mathrm{CD} 9^{-} \mathrm{CD} 25^{+}$ & $42.7 \pm 13.6$ & 16 & $40.3 \pm 13.0$ & 16 & $p=0.539$ & $41.4 \pm 12.5$ & $41.6 \pm 14.1$ & 16 & $43.4 \pm 13.2$ & $42.1 \pm 14.8$ & 8 & $39.3 \pm 12.4$ & $41.2 \pm 14.4$ & 8 & $p=0.836$ & $p=0.483$ & $p=0.183$ \\
\hline $\mathrm{CD} 9^{+} \mathrm{CD} 25^{-}$ & $2.8 \pm 2.5$ & 16 & $4.0 \pm 3.5$ & 16 & $p=0.323$ & $3.7 \pm 3.5$ & $3.0 \pm 2.6$ & 16 & $3.0 \pm 2.8$ & $2.6 \pm 2.2$ & 8 & $4.5 \pm 4.1$ & $3.5 \pm 3.0$ & 8 & $p=0.013$ & $p=0.233$ & $p=0.028$ \\
\hline $\mathrm{CD}_{69}{ }^{+} \mathrm{CD} 25^{+}$ & $2.0 \pm 2.0$ & 16 & $2.7 \pm 2.1$ & 16 & $p=0.184$ & $2.5 \pm 2.1$ & $2.2 \pm 2.0$ & 16 & $2.1 \pm 2.1$ & $1.9 \pm 2.0$ & 8 & $2.9 \pm 2.2$ & $2.6 \pm 2.2$ & 8 & $p=0.046$ & $p=0.171$ & $p=0.149$ \\
\hline $\mathrm{CD}^{+}{ }^{\mathrm{C} D} 45 \mathrm{RA}^{-}$ & $13.9 \pm 3.0$ & 16 & $16.3 \pm 4.8$ & 16 & $p=0.184$ & $15.3 \pm 4.1$ & $14.9 \pm 4.2$ & 16 & $13.9 \pm 2.7$ & $14.0 \pm 3.4$ & 8 & $16.7 \pm 4.9$ & $15.9 \pm 5.0$ & 8 & $p=0.778$ & $p=0.866$ & $p=0.735$ \\
\hline CD69-CD25- & $46.9 \pm 12.2$ & 16 & $46.3 \pm 12.3$ & 16 & $p=0.590$ & $46.1 \pm 11.4$ & $47.0 \pm 13.1$ & 16 & $45.8 \pm 11.6$ & $48.0 \pm 13.5$ & 8 & $46.5 \pm 11.9$ & $46.1 \pm 13.5$ & 8 & $p=0.501$ & $p=0.326$ & $p=0.779$ \\
\hline $\mathrm{CD} 9^{-} \mathrm{CD} 25^{+}$ & $51.8 \pm 12.3$ & 16 & $51.6 \pm 12.4$ & 16 & $p=0.780$ & $52.0 \pm 11.6$ & $51.4 \pm 13.1$ & 16 & $52.8 \pm 11.8$ & $50.8 \pm 13.5$ & 8 & $51.2 \pm 12.1$ & $52.0 \pm 13.5$ & 8 & $p=0.605$ & $p=0.327$ & $p=0.575$ \\
\hline $\mathrm{CD} 9^{+} \mathrm{CD}^{2} 5^{-}$ & $0.6 \pm 0.3$ & 16 & $0.9 \pm 0.8$ & 16 & $p=0.239$ & $0.8 \pm 0.7$ & $0.6 \pm 0.6$ & 16 & $0.6 \pm 0.3$ & $0.5 \pm 0.3$ & 8 & $1.1 \pm 0.8$ & $0.8 \pm 0.9$ & 8 & $p=0.007$ & $p=0.066$ & $p=0.041$ \\
\hline $\mathrm{CD}{ }^{+}{ }^{\mathrm{CD}} 25^{+}$ & $0.7 \pm 0.3$ & 16 & $1.2 \pm 1.0$ & 16 & $p=0.305$ & $1.0 \pm 0.8$ & $0.9 \pm 0.8$ & 16 & $0.8 \pm 0.4$ & $0.7 \pm 0.3$ & 8 & $1.3 \pm 1.0$ & $1.1 \pm 1.0$ & 8 & $p=0.045$ & $p=0.121$ & $p=0.180$ \\
\hline \multicolumn{18}{|l|}{ CD4- lymphocytes } \\
\hline CD4-CD45RA ${ }^{+}$ & $47.6 \pm 5.4$ & 16 & $43.7 \pm 7.3$ & 16 & $p=0.119$ & $47.5 \pm 5.1$ & $43.9 \pm 7.6$ & 16 & $48.2 \pm 5.1$ & $47.1 \pm 5.9$ & 8 & $46.8 \pm 5.4$ & $40.7 \pm 8.1$ & 8 & $p=0.009$ & $p=0.401$ & $p=0.012$ \\
\hline CD69-CD25- & $91.4 \pm 7.2$ & 16 & $90.4 \pm 7.0$ & 16 & $p=0.491$ & $90.2 \pm 7.7$ & $91.6 \pm 6.3$ & 16 & $90.7 \pm 8.3$ & $92.2 \pm 6.4$ & 8 & $89.7 \pm 7.6$ & $91.1 \pm 6.7$ & 8 & $p=0.039$ & $p=0.161$ & $p=0.093$ \\
\hline $\mathrm{CD} 69^{+}{ }^{-} D 25^{-}$ & $8.0 \pm 7.0$ & 16 & $9.1 \pm 7.1$ & 16 & $p=0.539$ & $9.3 \pm 7.7$ & $7.8 \pm 6.4$ & 16 & $8.8 \pm 8.0$ & $7.2 \pm 6.3$ & 8 & $9.8 \pm 7.9$ & $8.3 \pm 6.8$ & 8 & $p=0.016$ & $p=0.093$ & $p=0.093$ \\
\hline CD4-CD45RA- & $24.1 \pm 5.6$ & 16 & $23.8 \pm 10.3$ & 16 & $p=0.402$ & $21.7 \pm 5.7$ & $26.2 \pm 9.7$ & 16 & $23.0 \pm 5.6$ & $25.2 \pm 5.8$ & 8 & $20.3 \pm 5.8$ & $27.3 \pm 12.8$ & 8 & $p=0.019$ & $p=0.123$ & $p=0.123$ \\
\hline CD69-CD25- & $93.5 \pm 2.1$ & 16 & $89.0 \pm 9.5$ & 16 & $p=0.094$ & $91.2 \pm 6.2$ & $91.3 \pm 8.2$ & 16 & $93.3 \pm 2.0$ & $93.7 \pm 2.3$ & 8 & $89.1 \pm 8.2$ & $88.9 \pm 11.2$ & 8 & $p=0.836$ & $p=0.484$ & $p=0.779$ \\
\hline $\mathrm{CD} 9^{+} \mathrm{CD}^{25} 5^{-}$ & $5.3 \pm 2.3$ & 16 & $10.4 \pm 9.4$ & 16 & $p=0.032$ & $7.7 \pm 6.4$ & $8.0 \pm 8.2$ & 16 & $5.2 \pm 2.4$ & $5.5 \pm 2.4$ & 8 & $10.3 \pm 8.2$ & $10.6 \pm 11.1$ & 8 & $p=0.918$ & $p=0.889$ & $p=1.000$ \\
\hline \multicolumn{18}{|c|}{ Expression of activation markers in cytotoxic lymphocytes } \\
\hline \multicolumn{18}{|c|}{ CD8 $8^{+}$cytotoxic $T$ cells } \\
\hline $\mathrm{CD}^{+}{ }^{+} \mathrm{CD} 8^{+} \mathrm{IFN}^{+}$ & $6.0 \pm 4.8$ & 16 & $7.1 \pm 5.7$ & 16 & $p=0.468$ & $7.0 \pm 5.4$ & $6.1 \pm 5.0$ & 16 & $6.7 \pm 5.7$ & $5.3 \pm 3.8$ & 8 & $7.2 \pm 5.5$ & $7.0 \pm 6.2$ & 8 & $p=0.427$ & $p=0.779$ & $p=0.398$ \\
\hline $\mathrm{CD}^{+}{ }^{\mathrm{C}} \mathrm{C} 8+\mathrm{IL}-12 \mathrm{R}^{+}$ & $4.6 \pm 1.7$ & 16 & $5.4 \pm 2.2$ & 16 & $p=0.590$ & $5.0 \pm 2.1$ & $5.0 \pm 2.0$ & 16 & $4.7 \pm 2.0$ & $4.6 \pm 1.5$ & 8 & $5.2 \pm 2.3$ & $5.5 \pm 2.3$ & 8 & $p=0.660$ & $p=0.944$ & $p=0.441$ \\
\hline $\mathrm{CD}^{+}{ }^{+} \mathrm{CD} 8+\mathrm{IL}-15 \mathrm{R}^{+}$ & $8.4 \pm 4.5$ & 18 & $9.6 \pm 5.3$ & 16 & $p=0.422$ & $9.5 \pm 4.9$ & $8.4 \pm 4.9$ & 17 & $8.6 \pm 4.5$ & $8.2 \pm 4.7$ & 9 & $10.5 \pm 5.4$ & $8.7 \pm 5.4$ & 8 & $p=0.218$ & $p=0.678$ & $p=0.182$ \\
\hline $\mathrm{CD}^{+} \mathrm{CD} 8^{+} \mathrm{LL}-21 \mathrm{R}^{+}$ & $7.2 \pm 2.8$ & 16 & $8.6 \pm 3.6$ & 16 & $p=0.341$ & $8.1 \pm 3.5$ & $7.7 \pm 3.0$ & 16 & $7.1 \pm 3.5$ & $7.2 \pm 2.1$ & 8 & $9.0 \pm 3.5$ & $8.2 \pm 3.8$ & 8 & $p=0.642$ & $p=0.575$ & $p=0.208$ \\
\hline $\mathrm{CD}^{+}{ }^{+} \mathrm{CD} 8{ }^{+} \mathrm{CD} 107 \mathrm{a}^{+}$ & $5.8 \pm 2.3$ & 18 & $5.3 \pm 1.8$ & 16 & $p=0.851$ & $5.7 \pm 2.0$ & $5.5 \pm 2.2$ & 18 & $6.0 \pm 2.1$ & $5.6 \pm 2.7$ & 9 & $5.3 \pm 2.0$ & $5.3 \pm 1.8$ & 9 & $p=1.000$ & $p=0.767$ & $p=0.799$ \\
\hline \multicolumn{18}{|l|}{ Natural killer cells } \\
\hline $\mathrm{CD}^{-}{ }^{-C D 56} 6^{+} \mathrm{FN}^{+}$ & $21.1 \pm 2.1$ & 14 & $23.1 \pm 15.7$ & 14 & $p=0.946$ & $21.9 \pm 14.5$ & $22.2 \pm 13.5$ & 14 & $22.6 \pm 13.4$ & $19.5 \pm 11.5$ & 7 & $21.3 \pm 16.7$ & $24.9 \pm 15.7$ & 7 & $p=0.683$ & $p=0.176$ & $p=0.612$ \\
\hline $\mathrm{CD}^{-}{ }^{-\mathrm{CD}} 56^{+} \mathrm{IL}^{2} 12 \mathrm{R}^{+}$ & $11.2 \pm 5.3$ & 16 & $13.2 \pm 6.5$ & 16 & $p=0.838$ & $11.9 \pm 5.7$ & $12.5 \pm 6.3$ & 16 & $11.0 \pm 5.3$ & $11.5 \pm 5.7$ & 8 & $12.8 \pm 6.2$ & $13.5 \pm 7.2$ & 8 & $p=0.642$ & $p=0.889$ & $p=0.674$ \\
\hline $\mathrm{CD}^{-}{ }^{-\mathrm{CD}} 56^{+} \mathrm{IL} 15 \mathrm{R}^{+}$ & $17.9 \pm 11.5$ & 18 & $20.0 \pm 9.9$ & 18 & $p=0.355$ & $20.3 \pm 12.9$ & $17.6 \pm 7.7$ & 18 & $18.4 \pm 14.8$ & $17.3 \pm 7.6$ & 9 & $22.1 \pm 11.3$ & $17.8 \pm 8.3$ & 9 & $p=0.356$ & $p=0.889$ & $p=0.214$ \\
\hline CD3-CD56+IL-21R+ & $17.8 \pm 6.9$ & 16 & $21.7 \pm 10.2$ & 16 & $p=0.381$ & $20.1 \pm 8.5$ & $19.3 \pm 9.4$ & 16 & $16.9 \pm 5.8$ & $18.6 \pm 8.2$ & 8 & $23.4 \pm 9.8$ & $20.0 \pm 11.0$ & 8 & $p=0.679$ & $p=0.484$ & $p=0.327$ \\
\hline $\mathrm{CD}^{-}{ }^{-C D 56}{ }^{+} \mathrm{CD} 107 \mathrm{a}^{+}$ & $15.7 \pm 5.9$ & 18 & $16.1 \pm 6.9$ & 16 & $p=0.746$ & $15.1 \pm 6.5$ & $16.7 \pm 6.2$ & 17 & $14.7 \pm 4.8$ & $16.8 \pm 7.0$ & 9 & $15.6 \pm 8.4$ & $16.5 \pm 5.7$ & 8 & $p=0.044$ & $p=0.038$ & $p=0.397$ \\
\hline
\end{tabular}

$M$, male; $F$, female; $n$, number of samples.

Statistical significance achieved where $p<0.05$. 


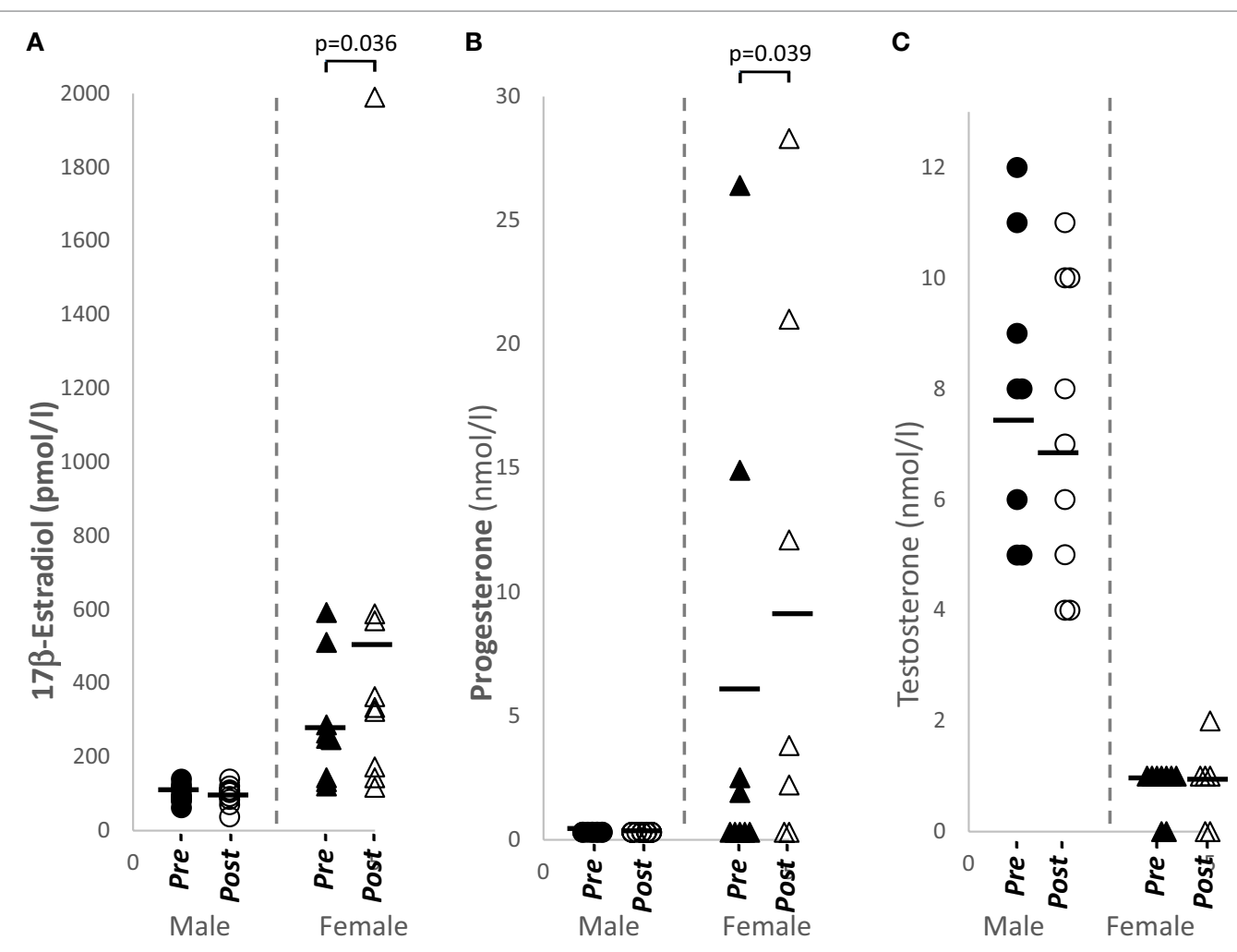

FIGURE 1 | Distribution of sex hormone levels in healthy human males $(N=9)$ and females $(N=9)$, pre- and post-papaya consumption. (A) $17 \beta$-estradiol, (B) progesterone, and (C) testosterone. *Statistical significance achieved where $p<0.05$.
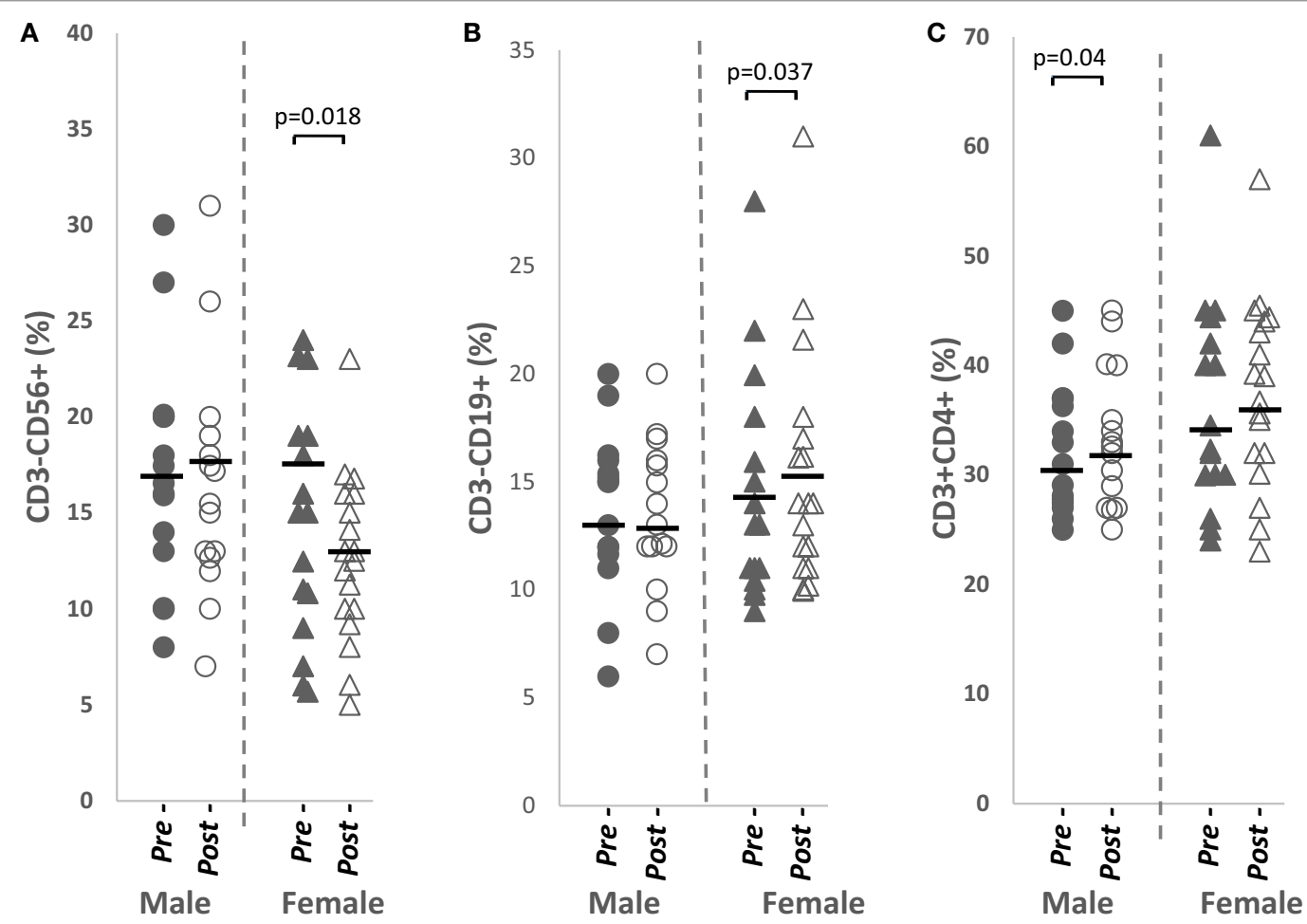

FIGURE 2 | Distribution of $(\mathbf{A})$ total CD3-CD56 ${ }^{+}$NK cells, (B) total CD3-CD19+ B cells, and $\mathbf{( C )}$ total CD3 ${ }^{+}$CD4 ${ }^{+}$helper T cells percentages in healthy males $(n=15)$ and females $(n=18)$ pre- and post-papaya consumption. *Statistical significance achieved where $p<0.05$. 
correlation was observed between sex hormone and total B cells in females or total $\mathrm{CD} 4^{+} \mathrm{T}$ cells in males.

\section{$\mathrm{CD} 9^{+} \mathrm{T}$ Cells Were Significantly Reduced after Papaya Consumption}

Three differentiation markers (CD45RA, CD69, and CD25) were selected from literature based on their use as naïve and activated/ effector markers (Figure 3A). Table 1 shows comparable percentages of naïve, $\mathrm{CD} 4{ }^{+} \mathrm{CD} 45 \mathrm{RA}^{+}$and non-naïve, $\mathrm{CD} 4^{+} \mathrm{CD} 45 \mathrm{RA}^{-} \mathrm{T}$ helper cells. Among naïve cells, the double negative, $\mathrm{CD} 69^{-} \mathrm{CD} 25^{-}$ subpopulation made up a major proportion followed by $\mathrm{CD} 9^{-} \mathrm{CD} 25^{+}$single positive cells. Within non-naive cells, mean percentage of the double negative subpopulation was lower while $\mathrm{CD}^{-} 9^{-} \mathrm{CD} 25^{+}$cells were higher (Table 1 ).

CD69 expression $\left(\mathrm{CD} 25^{+} / \mathrm{CD} 25^{-}\right)$was observed on only a small fraction (2.0-4.0\%) of naïve cells and was lower (0.6-1.2\%) among non-naïve Thelper cells (Table 1). The non-naïve (CD45RA ${ }^{-}$) component consisted of activated, effector, memory as well as regulatory cells, thus these cells may also be referred as activated cells here.

A relatively large mean percentage of $\mathrm{CD} 25^{+}$cells was observed in the naive component (40-45\%) and was higher in activated $\mathrm{CD}^{+} \mathrm{T}$ cells (Table $\mathbf{1}$ ).

All CD69-expressing $\mathrm{T}$ cells, either single $\mathrm{CD} 69^{+} \mathrm{CD} 25^{-}$or double positive $\mathrm{CD} 69^{+} \mathrm{CD} 25^{+}$were in general, significantly downregulated in naïve and activated subpopulations after papaya consumption (Figure 3B; Table 1). Correlation analysis with sex hormones revealed negative associations $[R \leq(-) 0.591]$ with progesterone in females and testosterone in males but these associations were insignificant ( $p \geq 0.116$ ).

Correlation analysis between sex hormones and CD25expressing cells, however, revealed significant strong negative associations between changes in testosterone levels and percentages of CD25-expressing T helper cells, in a naïve CD4 ${ }^{+} \mathrm{CD} 45 \mathrm{RA}$ ${ }^{+} \mathrm{CD} 9^{-} \mathrm{CD} 25^{+}(R=-0.899, p=0.002, n=8)$ and the activated subpopulations, $\mathrm{CD} 4{ }^{+} \mathrm{CD} 45 \mathrm{RA}^{-} \mathrm{CD} 69^{-} \mathrm{CD} 25^{+}(R=-0.894$, $p=0.003, n=8)$ and $\mathrm{CD}^{+} \mathrm{CD} 45 \mathrm{RA}^{-} \mathrm{CD} 69^{+} \mathrm{CD} 25^{+}(R=-0.852$, $p=0.007, n=8)$, in males following papaya consumption (Figure 2). A "mirror image" significant strong positive correlations were observed between testosterone with double-negative $\left(\mathrm{CD}^{-} 9^{-} \mathrm{CD} 25^{-}\right)$naive $(R=0.894, p=0.003, n=8)$ and activated $(R=0.899, p=0.002, n=8) \mathrm{CD}^{+} \mathrm{T}$ cells (Table $\left.\mathbf{1}\right)$.

Progesterone also had an apparent suppressive effect on CD $25^{+}$ cells in females, as negative correlations were observed with single positive, naive $\mathrm{CD} 45 \mathrm{RA}^{+} \mathrm{CD} 69^{-} \mathrm{CD}^{2} 5^{+}(R=-0.524, p=0.183$,

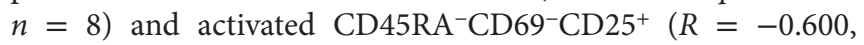
$p=0.116, n=8)$ T helper cells, following papaya consumption. The relation, however, was not as strong as testosterone in males.

\section{Total Naïve Non-CD4+ Lymphocytes Were Significantly Reduced while Total Activated Non-CD4 ${ }^{+}$Lymphocytes Significantly Increased after Papaya Consumption}

Non-CD4 $4^{+}\left(\mathrm{CD}^{-}\right)$lymphocytes were a mixed population consisting of CD8 T cells, NK, B and NKT subsets. CD25 positivity was very low among these cells, $<1 \%$ (data not shown) and excluded from further analysis.

The majority of non-CD4 $4^{+}$lymphocytes, were double negative $\left(\mathrm{CD} 69^{-} \mathrm{CD} 25^{-}\right)$. Compared to $\mathrm{CD} 4^{+}$lymphocytes where expression of CD69 was found on $0.6-4.0 \%$, a larger population of $\mathrm{CD} 9^{+}$cells was observed among the non-CD $4^{+}$lymphocytes forming average percentages of $8.0-9.1 \%$ in $\mathrm{CD}_{45 \mathrm{RA}^{+}}$and $5.3-10.4 \%$ in CD45RA- lymphocytes (Table 1).

Total naïve non-CD $4^{+}$lymphocytes were significantly reduced while the activated populations were significantly increased after papaya consumption (Table 1). Distribution of pre- and postpapaya consumption percentages are shown in Figure 3C. Among naïve cells, the $\mathrm{CD} 69^{+} \mathrm{CD} 25^{-}$subpopulations were significantly reduced while the corresponding double negative $\left(\mathrm{CD} 69^{-} \mathrm{CD} 25^{-}\right)$ subpopulations were significantly increased (Table 1). Within the activated population, changes were not significant as modulations were more heterogeneous between individual subjects which resulted in less obvious total effect. Interestingly, $\mathrm{CD}^{+} 9^{+} \mathrm{CD} 25^{-}$subpopulations were larger in females, particularly the significantly higher activated $\mathrm{CD}^{-} \mathrm{CD} 45 \mathrm{RA}^{-} \mathrm{CD} 69^{+} \mathrm{CD} 25^{-}$ subpopulation (Table 1). Negative correlations were observed between naïve and activated $\mathrm{CD}^{+} 9^{+}$subpopulations and testosterone in males $(R=-0.728, p=0.041, n=8$ and $R=-0.664$, $p=0.073, n=8$, respectively) as well as progesterone in females $(R=-0.434, p=0.282, n=8$ and $R=-0.668, p=0.070 . n=8$, respectively), though the majority of these correlations were not significant.

Interesting also to note, CD69 expression was associated with two divergent levels of CD45RA expression, i.e., CD45RA ${ }^{\text {hi }} \mathrm{CD} 69^{+}$

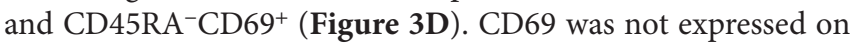
cells with intermediate levels of CD45RA. These may be useful in differentiating circulating regulatory cells/early activated cells before cell division, and memory/effector cells/migrating Tregs, respectively.

\section{No Significant Change in CD8 ${ }^{+} \mathrm{T}$ Cell Subsets Expressing Effector Markers after Papaya Consumption}

The distinctly increased activated non-CD4 ${ }^{+}$cells after papaya consumption prompted a closer examination of this population, consisting of $\mathrm{CD}^{+} \mathrm{T}$ cells, B cells, NK cells, or NKT cells. We opted for the cytotoxic component for further analysis and selected several activation markers associated with these cells. Effector markers analyzed were IFN- $\gamma$, IL-12R2 $\beta$, IL- $15 R \alpha$, IL-21R, and degranulation marker, CD107a.

No significant changes were observed in $\mathrm{CD}^{+} \mathrm{T}$ cells expressing any of these markers (Table 1).

\section{Significantly Increased CD107a ${ }^{+}$NK Cells after Papaya Consumption}

The same effector markers were analyzed on NK cells $\left(\mathrm{CD} 3^{-} \mathrm{CD} 56^{+}\right)$. By comparison, these markers were expressed on a larger percentage of NK cells compared to $\mathrm{CD} 8^{+} \mathrm{T}$ cells (Table $\mathbf{1}$ ).

Overall, a significant upregulation of $\mathrm{CD} 107 \mathrm{a}^{+} \mathrm{NK}$ cells was observed after papaya consumption (Figure 4B; Table 1) 


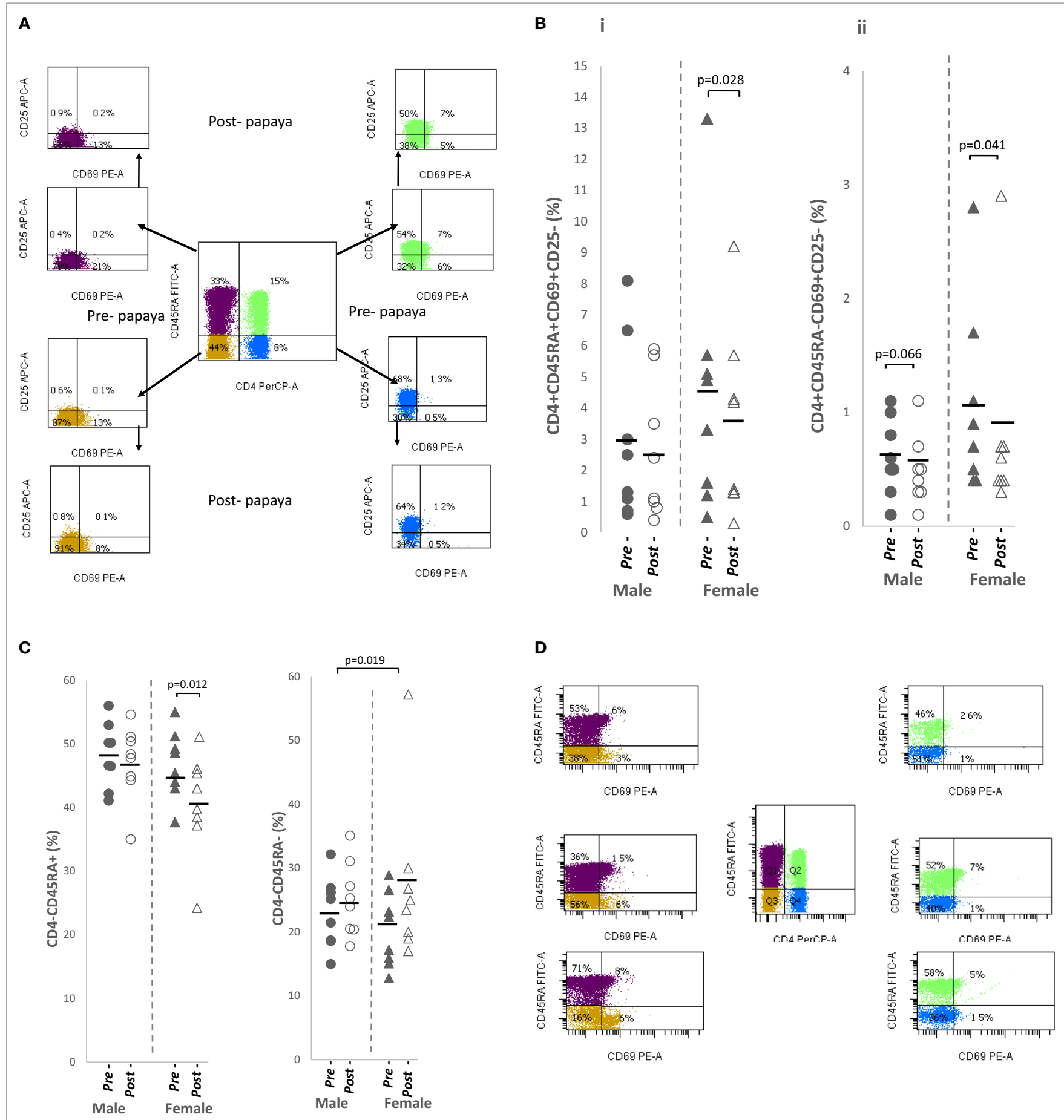

FIGURE 3 | (A) Flow cytometry gating strategy for analysis of differentiation markers expressed on CD4+ $\mathrm{T}$ cells/non-CD4+ lymphocytes in lysed whole blood. Initial

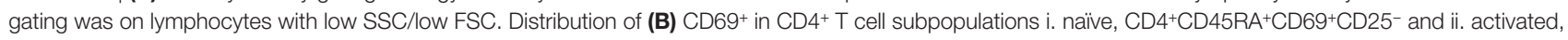

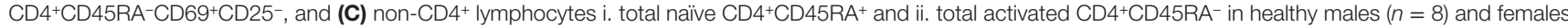
$(n=8)$ pre- and post-papaya consumption. (D) Representative flow cytometry plots showing CD69+ fractions in naïve, CD45RA+ and activated CD45RA- CD4+ T cells and non-CD4+ lymphocytes. *Statistical significance achieved where $p<0.05$.

particularly in males. Representative flow cytometry plots demonstrating gating strategy to detect CD107a expression on cytotoxic cells are shown in Figure 4A.
Correlation analysis revealed CD107a $\mathrm{a}^{+} \mathrm{NK}$ cells no strong correlation with testosterone levels in males $(R=0.520, p=0.151$, $n=9)$ but demonstrated strong positive association $(R=0.771$, 

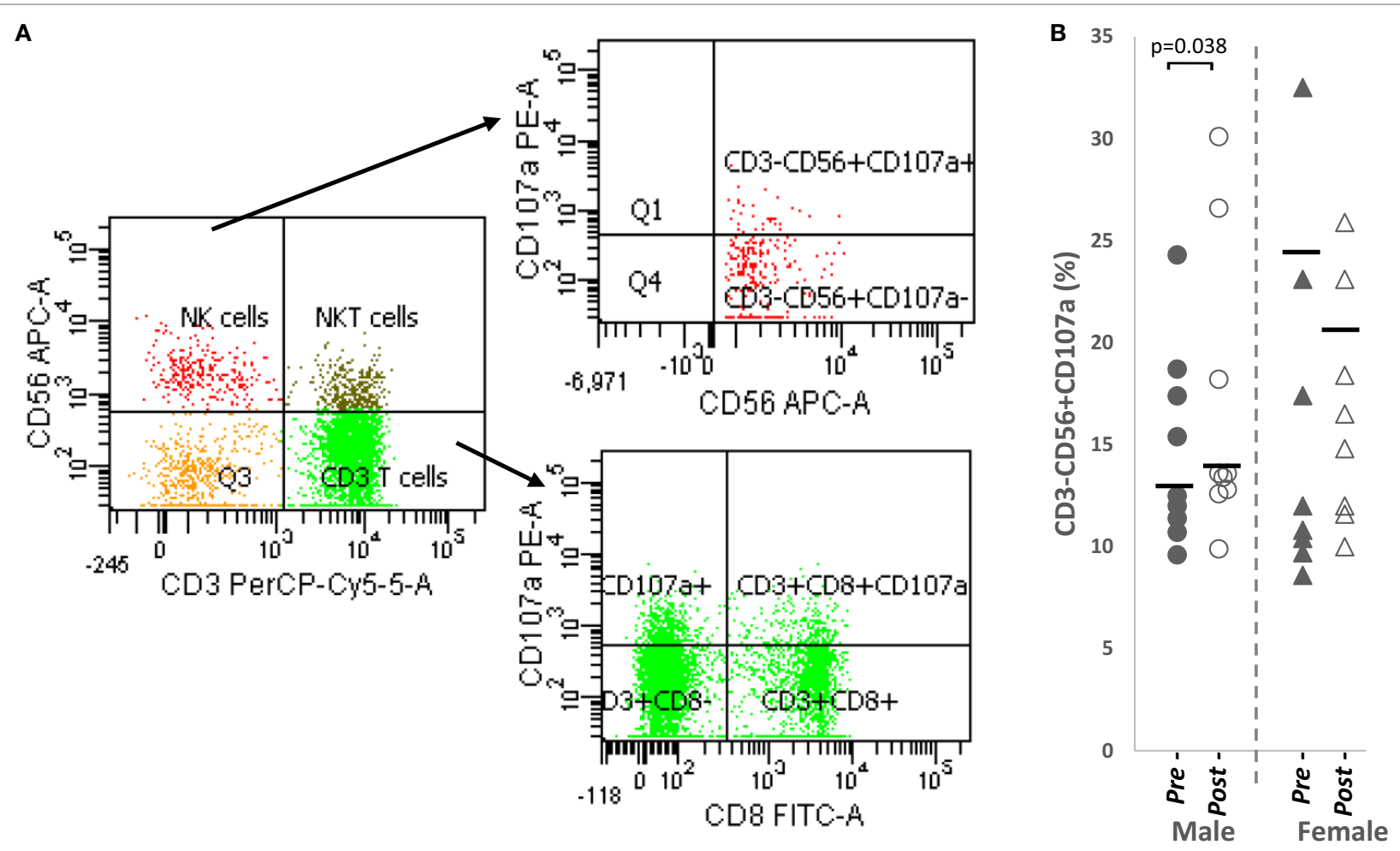

FIGURE 4 | (A) Flow cytometry gating strategy to analyze degranulation marker, CD107a on $\mathrm{CD}^{+} \mathrm{CD}^{+}{ }^{+}$cytotoxic $\mathrm{T}$ cells and $\mathrm{CD} 3^{-} \mathrm{CD} 56^{+} \mathrm{NK}$ cells. Initial gating was on lymphocytes with low SSC/low FSC (B) distribution of CD107a NK cell percentages in healthy male $(n=9)$ and females $(n=8)$ pre- and post-papaya consumption. *Statistical significance achieved where $p<0.05$.

$p=0.025, n=8)$ with progesterone in females. Thus, while papaya generally induced NK cell degranulation, in females, this occurred only in increased progesterone.

\section{DISCUSSION}

In this study, the feasibility of detecting endo-immunomodulation by dietary intake of Carica papaya fruit was explored in an oral sensory receptive model involving a small population of apparently healthy individual. This preliminary, 2-day short-term exposure revealed interesting results.

Exogenous supplementation from plant-based hormones may affect outcomes in the study as fruits and vegetables contain a myriad of phytochemicals including phytoestrogens. However, a study on premenopausal women given isoflavone-rich diets was not shown to affect serum estradiol or progesterone concentrations (19).

We observed significantly increased $17 \beta$-estradiol (E2) and progesterone (P4) in females after papaya consumption. Researches on effects of whole fruits on sex hormones in premenopausal women are limited. In the BioCycle Study on healthy premenopausal women, increased intake of citrus fruit juice did not alter estradiol levels but increased progesterone levels. No significant changes were observed, however, with increased intake of non-citrus fruit juice (20). In healthy postmenopausal women, whole grapefruit significantly increased estrone-3-sulfate (E1S) while fresh juice, bottled juice, and soda intake significantly lowered estradiol (E2) (21). Pomegranate juice reduced estrone (E1) and testosterone in normal weight postmenopausal women (22). Thus, our results support evidence of potential sex hormone alterations from intake of fruits in women.

Estrogen receptor (ER) and progesterone receptors are expressed on various lymphocytes [reviewed in Ref. (23)]. Total NK cell percentages significantly reduced in females consuming papaya in this study was shown to have a negative association with $17 \beta$-estradiol. Several conditions have shown that NK cell counts are decreased by estrogen. Peripheral NK cells are reduced during pregnancy (24). In vivo application of ethinyl estradiol in transsexual male resulted in significant decrease in percentages of NK cells (25). These studies support our observation and suggest increased estradiol levels in females may have contributed to reduced percentage of NK cells in females.

Other researchers found estrogen replacement therapy in postmenopausal women especially increased B-lymphocyte numbers and decreased pro-inflammatory cytokine production $(26,27)$. ER $\beta$ is upregulated in B cells $(23)$. The increased $17 \beta$-estradiol levels and total $\mathrm{B}$ cells seen here may be similar responses as reported.

Differentiation markers such as CD45RA, CD69, and CD25 are extensively used in literature but comparison across lymphocyte subpopulations in the system is few. Human naive and memory T cells have been identified by the reciprocal expression 
of the CD45RA and CD45RO isoforms. The peripheral blood reportedly, contains a comparable proportion of CD45RO ${ }^{+}$and CD45RA ${ }^{+}$subsets (28), as was similarly observed here.

CD69 and CD25 are regarded as early and late activation markers, respectively, as an early peak in expression $(24 \mathrm{~h})$ of CD69 and a later (48 h) peak in expression of CD25 after in vitro phytohemagglutination (PHA) stimulation of CD45RA/CD45RO CD4 ${ }^{+}$ $\mathrm{T}$ cell subsets were observed (29). Since then, CD69 expression has been induced in vitro on cells of most hematopoietic lineages, including $\mathrm{T}$ and B lymphocytes, NK cells, murine macrophages, neutrophils, and eosinophils, while it is constitutively expressed on human monocytes, platelets, and epidermal Langerhans cells (30).

Even though, the specific ligand for CD69 has not been identified and the role of CD69 is currently intensively investigated. CD69-expressing $\mathrm{T}$ cells, $\mathrm{CD} 4{ }^{+} \mathrm{CD} 69^{+} \mathrm{CD} 25^{-}$has been proposed as a novel regulatory cell type defined by TGF- $\beta 1$ activity (31). The suppressive function of Tregs is dependent on CD69 expression, which forms approximately fifty percent of total $\mathrm{CD}^{+} \mathrm{CD} 25^{+} \mathrm{FoxP}^{+}$Tregs in thymus and secondary lymphoid organs (32). Another major function, however, is involvement in immune cell migration. CD69 is expressed at high levels on approximately $10-15 \%$ of thymocytes and play a role in selection and maturation processes in the thymus (33). This may explain the small fraction of $\mathrm{CD} 9^{+}$cells (CD25 \pm ) found among naive $\left(\mathrm{CD} 45 \mathrm{RA}^{+}\right)$Thelper cells in this study. A study on tissues acquired from deceased organ donors, however, showed CD45RA ${ }^{+} \mathrm{T}$ cells were predominantly CD69 negative, including $100 \%$ of naive $\mathrm{T}$ cells in blood (28).

Brenchley et al. (34) examined expressions of differentiation markers in activated, proliferated and effector $\mathrm{T}$ cells after in vitro stimulation. $\mathrm{CD} 25$ and $\mathrm{CD} 45 \mathrm{RO}$ become expressed on activated cells prior to cell division and maintained thereafter. CD45RA and CD69 were both down-modulated in a cell division dependent fashion, i.e., mitotic dilution, after stimulation. An expansion period for activated naïve T-cells may be more important before acquisition of effector function, after which some differentiate into resting, antigen-experienced T-cells. These results correspond with observations here where CD69 expression was lower in the non-naive/activated population. This also suggested that activated cells $\left(\mathrm{CD} 9^{+}\right)$were in the "naïve" populations. Furthermore, migratory role of CD69 has also been demonstrated following activation. In inflamed lymph nodes, CD69 is upregulated on lymphocytes, which control its movements within (35). A small fraction (1-20\%) of circulating memory $\left(\mathrm{CD} 45 \mathrm{RO}^{+}\right)$cells express CD69 (28). CD69 mediates homing and retention of $\mathrm{CD} 4^{+} \mathrm{T}$ memory cells in the bone marrow (36).

Expression of CD25 has typically been associated with activated cells. However, we observed a large fraction of $\mathrm{CD} 25^{+}$cells (40-45\%) among naïve Thelper cells. Using an extensive number of activation, differentiation, and exhaustion markers combined with microarray analysis, Pekalski et al. (37) confirmed existence of a subset of naive $\mathrm{CD} 4{ }^{+} \mathrm{CD} 45 \mathrm{RA}{ }^{+} \mathrm{T}$ cells that express $\mathrm{CD} 25$. The percentage of $\mathrm{CD} 4^{+} \mathrm{CD} 25^{+}$naive $\mathrm{T}$ cells was strongly associated with increasing age and were also detected in cord blood, indicating that acquisition of $\mathrm{CD} 25$ expression by naive $\mathrm{CD} 4 \mathrm{~T}$ cells begins prior to birth (25). CD25 induction in naïve cells occurs through TCR signaling which, however, are not strong enough to lead to $\mathrm{T}$ cell activation and loss or acquisition of markers characterizing effector or memory cells but is important for expansion in the periphery of a naive TCR repertoire particularly after the period of thymic involution. These cells respond faster and better to low dose IL-2 compared to their CD25- counterpart (37). CD25 is also highly expressed on regulatory $\mathrm{T}$ cells. It is now apparent that the naive $\mathrm{CD} 45 \mathrm{RA}^{+}$subpopulation of $\mathrm{CD} 4^{+} \mathrm{CD} 25^{\text {hi }} \mathrm{FoxP} 3^{\text {lo }}$ $\mathrm{T}$ cells in blood is the most suitable target population for in vitro expansion of regulatory $\mathrm{T}$ cells (38). These resting Treg cells are induced into activated Tregs to become CD45RA-FoxP $3^{\text {hi }}$ cells, a population also observed in peripheral blood of healthy individuals (39).

$\mathrm{CD}^{2} 5^{+}$percentages are higher in non-naïve $\mathrm{T}$ helper cells as was seen here. Resting memory T-cells may be CD25-, i.e., late differentiated cells that respond to antigens associated with chronic immune responses. The majority however, are CD25(INT) memory $\mathrm{T}$ cells that respond to antigens associated with recall responses, produce a greater array of cytokines, and are less dependent on co-stimulation for effector responses due to their expression of CD25 (40).

Many studies have shown levels of $\mathrm{CD} 4^{+} \mathrm{T}$ cells are lower in males compared to females [reviewed in Ref. (23)] as was also observed here. We detected strong negative associations between testosterone and CD25-expressing T cells. These were consistent with another report showing suppressive effect of testosterone on $\mathrm{CD} 25^{+} \mathrm{CD} 45 \mathrm{RA}^{+}$and $\mathrm{CD} 25^{+} \mathrm{CD} 45 \mathrm{RO}^{+} \mathrm{T}$ cells (41). Medical castration reduced testosterone levels and increased $\mathrm{CD} 4{ }^{+} \mathrm{CD} 25^{+}$cells (42). Thus, testosterone appeared to target the $\mathrm{CD}_{2} 5^{+}$marker. The action of testosterone on the $\mathrm{CD} 25^{+}$cells may be to induce cell death as testosterone is shown to induce apoptosis in T cells (43). We also observed decreased percentages of the major populations of $\mathrm{CD} 25^{+}$ cells $\quad\left(\mathrm{CD} 4{ }^{+} \mathrm{CD} 45 \mathrm{RA}^{+} \mathrm{CD} 69^{-} \mathrm{CD} 25^{+} / \mathrm{CD} 4^{+} \mathrm{CD} 45 \mathrm{RA}{ }^{+} \mathrm{CD} 69\right.$ ${ }^{-} \mathrm{CD} 25^{+}$) in males (but not in females) as the majority of male subjects maintained/increased testosterone levels after papaya consumption.

In reverse, $\mathrm{CD} 25^{-}$cells, both naïve and activated were increased in males (but not females) after papaya consumption. This may be a homeostatic response [discussed in Ref. (44)] in an effort to return $\mathrm{T}$ cells to normal levels by inducing proliferation of naïve cells $\left(\mathrm{CD} 4^{+} \mathrm{CD} 45^{+} \mathrm{CD} 69^{-} \mathrm{CD} 25^{-}\right)$, which are dominant and robust having indefinite life span. In the presence of androgen, CD4 T cell differentiation inhibition was also demonstrated by significantly reduced levels of Tbet and IFN- $\gamma(45)$ possibly mediated through upregulation of $\mathrm{CD} 4^{+} \mathrm{CD} 25^{+} \mathrm{Foxp} 3^{+}$regulatory $T$ cells (46). In an earlier study, we also demonstrated increased regulatory $\mathrm{T}$ cells after papaya consumption (47). The accumulative effect may have been to increase slightly the percentage of $\mathrm{CD} 4^{+} \mathrm{T}$ cells in males, observed here.

The low expression of $\mathrm{CD} 25$ on non- $\mathrm{CD} 4^{+}$lymphocytes is consistent with other reports; immature B and certain NKT subsets may express low levels of CD25. Mature B cells, NK cells, and NKT are absent for CD25 (48). The alpha (CD25) chain is one of three subunits that make up the IL-2 receptor, the other two being beta (CD122), and gamma (gammac) chains. $\mathrm{CD}^{+}$ 
T cells preferentially express CD122 and naturally occurring $\mathrm{CD} 8^{+} \mathrm{CD} 122^{+} \mathrm{T}$ cells maintain $\mathrm{T}$ cell homeostasis as well as Treg function. Murine $\mathrm{CD} 8{ }^{+} \mathrm{CD} 122^{+}$Tregs carry CD122 or IL-2R $\beta$, but not $\mathrm{CD} 25$, while $\mathrm{CD} 4^{+} \mathrm{CD} 25^{+}$Tregs do not express $\mathrm{CD} 122$, although both subsets of Tregs are CD44 ${ }^{\text {high }}$, CD62 $\mathrm{L}^{\text {high }}$ and mostly CD127-negative [reviewed in Ref. (49)].

Consumption of papaya in general induced a suppressive effect on $\mathrm{CD} 69^{+}$cells, particularly $\mathrm{CD} 4^{+} \mathrm{T}$ helper cells as well as the naïve non-CD $4^{+}$lymphocytes. The potential of fruits to inhibit CD69 expression has been shown in the in vitro administration of auraptene, a citrus fruit-derived coumarin (50) and cactus pear fruit extract (51) on activated lymphocytes.

However, this effect was not similarly observed in activated non-CD4 $4^{+}$lymphocytes. Individual responses were heterogeneous and mean percentage was, in reverse, slightly increased after papaya consumption. Negative correlations were generally observed between $\mathrm{CD} 9^{+}$subpopulations with testosterone in males and progesterone in females. In fact, the negative correlation with this activated non- $\mathrm{CD} 4^{+}$lymphocyte was the strongest in females. The selective nature of progesterone is in concordance with reported evidence of progesterone suppression of uterine natural killer (NK) cells in human and spleen cells in mice expressing CD69 (52). In females, this population of cells appeared to be responsive to the effect of progesterone and resulted in reduced percentages in subjects increased for progesterone. Since not all subjects increased progesterone levels, overall effect of suppression was not significant. More importantly, in subjects with low levels of progesterone, percentages of these cells increased and were not affected by the presumed suppressive effect of papaya. In females, non-naïve $\mathrm{CD} 69^{+}$non-CD $4^{+}$lymphocytes formed a significantly larger population compared to males. This may also be due to the majority of females being in the follicular phase of the menstrual cycle with relatively lower levels of progesterone. We were unable to locate literature studying effect of testosterone on $\mathrm{CD} 9^{+}$lymphocytes.

The significantly increased NK cell degranulation $\left(\mathrm{CD} 107 \mathrm{a}^{+}\right)$ in males after papaya consumption appeared to be unaffected by sex hormone changes. Other studies strengthen this observation. NK cell activity of peripheral mononuclear cells against target $\mathrm{K} 562$ cells measured by the $51 \mathrm{Cr}$ release assay did not differ between patients with idiopathic hypogonadotropic hypogonadism (with significantly lower mean plasma testosterone) and healthy adults. Most importantly, this activity did not change during hormonal treatment, which normalized plasma testosterone levels in the patients (53). NK cells from normal donors exhibiting $\mathrm{K} 562$ lysis are shown to be $\mathrm{CD}^{2} 6^{+} \mathrm{CD} 69^{-}$. $\mathrm{CD} 56^{+} \mathrm{CD} 69^{+}$cells did not significantly increase cytotoxicity even though PMA stimulation increases CD69 expression on NK cells (54). Thus, CD107a NK cells may be CD69 negative. In an earlier study, we also observed significantly increased percentages of NK cells in males (but not females) after in vitro PHA activation. The lower response in females did not appear to involve $\mathrm{CD} 9^{+}$ cells, indirectly confirming no sex hormone effects in the in vitro study (55).

In females, increased NK degranulation activity was only observed when progesterone levels were also increased in subjects after papaya consumption. In vitro, no effect of progesterone on NK activity was demonstrated but women on oral contraceptive and fertile females in the luteal phase of the cycle have lower NK cell activity than males or post-menopausal women. During the follicular phase, these differences were not apparent. However, the effect may be either from estrogen or progesterone [reviewed in Ref. (56)]. Our results differ from reported evidence, as we observed progesterone may have stimulatory effect on NK activity. Thus, this remains controversial but the action of hormones may be dependent on status of cell activation.

Fruit extracts have been shown to modulate the immune system significantly even within a day of treatment $(11,13)$. Nevertheless, studies with long term treatments, e.g., of 33 days (12) to 70 days (10) also provide similar evidence of immunomodulatory responses. Thus, regular supplementation may continually induce an immune-related change. However, whether this is a desired change will be dependent on the purported outcome.

The inability to elicit similar sex hormonal changes in all subjects resulting in heterogeneous responses may be due to individual variability, insufficient stimulation with 2 days exposure or observations were just random changes to the physiological environment. However, the inclusion of the sex hormone markers in this study has clarified many dimorphism seen in immune responses that would not have been otherwise understood.

\section{CONCLUSION}

The vast knowledge available on the immune system allowed us to better interpret complex changes from normal exposures. The short-term papaya consumption experiment revealed sexual dimorphic changes in the immune system. Both stimulatory and suppressive effects were observed in lymphocyte subsets of healthy individuals after papaya consumption. Stimulation of $\mathrm{CD}^{+} \mathrm{T}$ cell percentages and NK cell activity in males suggest a beneficial potential from papaya consumption in this subset of individuals. Increased B cell percentages and reduced percentages of NK cells are characteristics of the female immune profile. It is not clear if "exacerbation" of these situations with papaya consumption may not be advantageous. Similarly, decreased naïve non-CD4 $4^{+}$lymphocytes seen in females may not be desirable. This study also revealed endocrine-immune system interactions, in particular, the possible suppressive effect of testosterone on CD25. Furthermore, low progesterone levels, e.g., during the follicular phase appeared to promote activated $\mathrm{CD} 9^{+}$non-CD $4^{+}$ lymphocytes but led to non-responsiveness in NK degranulation inducible by external factors such as papaya consumption, as observed here.

Due to a spectrum in expression of these markers across normal individuals, an overlap of phenotypes did occur between sexes, thus no strict "sex-labeled" boundaries existed. However, sex-biased responses were still distinguishable and sex hormone levels were able to provide a guide. The ability to measure immune response in vivo fulfills an important facet in the overall evaluation of immune health. The limitations of this study were the short supplementation period and the small number of samples analyzed. A larger number of subjects and a longer period of supplementation will be required to confirm these results. 


\section{ETHICS STATEMENT}

This study was approved by Medical Research Ethics Committee, Faculty of Medicine and Health Sciences, Universiti Putra Malaysia. All procedures complied with the principles of the Declaration of Helsinki. Informed consents were obtained.

\section{AUTHOR CONTRIBUTIONS}

MA, ZS, RJ, and WK contributed to the conception and design of the study. NJ, CY, and MA contributed to acquisition of data, analysis, and interpretation of data. MA and NJ drafted the article and revised it critically for important intellectual content. All authors approved the final the version to be submitted.

\section{REFERENCES}

1. Fischer J, Jung N, Robinson N, Lehmann C. Sex differences in immune responses to infectious diseases. Infection (2015) 43(4):399-403. doi:10.1007/ s15010-015-0791-9

2. Giefing-Kröll C, Berger P, Lepperdinger G, Grubeck-Loebenstein B. How sex and age affect immune responses, susceptibility to infections, and response to vaccination. Aging Cell (2015) 14(3):309-21. doi:10.1111/acel.12326

3. Garenne M. Demographic evidence of sex differences in vulnerability to infectious diseases. J Infect (2015) 211:331-2. doi:10.1093/infdis/jiu448

4. Fish EN. The X-files in immunity: sex-based differences predispose immune responses. Nat Rev Immunol (2008) 8:737-44. doi:10.1038/nri2394

5. Flanagan KL. Sexual dimorphism in biomedical research: a call to analyse by sex. Trans R Soc Trop Med Hyg (2014) 108:385-7. doi:10.1093/trstmh/tru079

6. McCombe PA, Greer JM, Mackay IR. Sexual dimorphism in autoimmune dis ease. Curr Mol Med (2009) 9(9):1058-79. doi:10.2174/156652409789839116

7. Gabory A, Roseboom TJ, Moore T, Moore LG, Junien C. Placental contribution to the origins of sexual dimorphism in health and diseases: sex chromosomes and epigenetics. BiolSexDiffer (2013) 4(1):5. doi:10.1186/20426410-4-5

8. Miller VM. Family matters: sexual dimorphism in cardiovascular disease. Lancet (2012) 379(9819):873-5. doi:10.1016/S0140-6736(12)60200-1

9. Markle JG, Fish EN. SeXX matters in immunity. Trends Immunol (2014) 35(3):97-104. doi:10.1016/j.it.2013.10.006

10. Percival SS. Grape consumption supports immunity in animals and humans. J Nutr (2009) 139(9):1801S-5S. doi:10.3945/jn.109.108324

11. Zhang W, Cho SY, Xiang G, Min KJ, Yu Q, Jin JO. Ginseng berry extract promotes maturation of mouse dendritic cells. PLoS One (2015) 10(6):e0130926. doi:10.1371/journal.pone.0130926

12. Deng YY, Yi Y, Zhang LF, Zhang RF, Zhang Y, Wei ZC, et al. Immunomodulatory activity and partial characterisation of polysaccharides from Momordica charantia. Molecules (2014) 19(9):13432-47. doi:10.3390/ molecules190913432

13. Monforte MT, Fimiani V, Lanuzza F, Naccari C, Restuccia S, Galati EM. Feijoa sellowiana Berg fruit juice: anti-inflammatory effect and activity on superoxide anion generation. J Med Food (2014) 17(4):455-61. doi:10.1089/ jmf.2012.0262

14. Ginwala R, McTish E, Raman C, Singh N, Nagarkatti M, Nagarkatti P, et al. Apigenin, a natural flavonoid, attenuates EAE severity through the modulation of dendritic cell and other immune cell functions. J Neuroimmune Pharmacol (2016) 11(1):36-47. doi:10.1007/s11481-015-9617-x

15. del Cornò M, Scazzocchio B, Masella R, Gessani S. Regulation of dendritic cell function by dietary polyphenols. Crit Rev Food Sci Nutr (2016) 56(5):737-47. doi:10.1080/10408398.2012.713046

16. Mahattanatawee K, Manthey JA, Luzio G, Talcott ST, Goodner K, Baldwin EA. Total antioxidant activity and fiber content of select Florida-grown tropical fruits. J Agric Food Chem (2006) 54:7355-63. doi:10.1021/jf060566s

\section{ACKNOWLEDGMENTS}

We would like to acknowledge the technical contributions of Marsitah Abdul Jalil and Amrina Mohamad Amin, and thank the participation of all volunteers.

\section{FUNDING}

This work was supported by a Universiti Putra Malaysia Research Grant (Project No: 04-01-11-1333RU).

\section{SUPPLEMENTARY MATERIAL}

The Supplementary Material for this article can be found online at http://journal.frontiersin.org/article/10.3389/fimmu.2017.00680/ full\#supplementary-material.

17. Koo HM, Mohamed S. Flavonoid (myricetin, quercetin, kaempferol, luteolin and apigenin) content of edible tropical plants. J Agric Food Chem (2001) 49:3106-12. doi:10.1021/jf000892m

18. Ikram EHK, Stanley R, Netzel M, Fanning K. Phytochemicals of papaya and its traditional health and culinary uses - a review. J Food Compos Anal (2015) 41:201-11. doi:10.1016/j.jfca.2015.02.010

19. Hooper L, Ryder JJ, Kurzer MS, Lampe JW, Messina MJ, Phipps WR, et al. Effects of soy protein and isoflavones on circulating hormone concentrations in pre- and post-menopausal women: a systematic review and metaanalysis. Hum Reprod Update (2009) 15(4):423-40. doi:10.1093/humupd/ dmp010

20. Schliep KC, Schisterman EF, Mumford SL, Pollack AZ, Perkins NJ, Ye A, et al. Energy-containing beverages: reproductive hormones and ovarian function in the BioCycle Study. Am J Clin Nutr (2013) 97(3):621-30. doi:10.3945/ ajcn.111.024752

21. Monroe KR, Stanczyk FZ, Besinque KH, Pike MC. The effect of grapefruit intake on endogenous serum estrogen levels in postmenopausal women. Nutr Cancer (2013) 65(5):644-52. doi:10.1080/01635581.2013.795982

22. Kapoor R, Ronnenberg A, Puleo E, Chatterton RT Jr, Dorgan JF, Seeram NP, et al. Effects of pomegranate juice on hormonal biomarkers of breast cancer risk. Nutr Cancer (2015) 67(7):1113-9. doi:10.1080/01635581.2015.1073756

23. Klein SL, Flanagan KL. Sex differences in immune responses. Nat Rev Immunol (2016) 16(10):626-38. doi:10.1038/nri.2016.90

24. Bouman A, Heineman MJ, Faas MM. Sex hormones and the immune response in humans. Hum Reprod Update (2005) 11(4):411-23. doi:10.1093/humupd/ dmi008

25. Giltay EJ, Fonk JC, von Blomberg BM, Drexhage HA, Schalkwijk C, Gooren LJ. In vivo effects of sex steroids on lymphocyte responsiveness and immunoglobulin levels in humans. J Clin Endocrinol Metab (2000) 85(4):1648-57. doi:10.1210/jcem.85.4.6562

26. Kamada M, Irahara M, Maegawa M, Yasui T, Takeji T, Yamada M, et al. Effect of hormone replacement therapy on postmenopausal changes of lymphocytes and T cell subsets. J Endocrinol Invest (2000) 23:376-82. doi:10.1007/ BF03343741

27. Porter VR, Greendale GA, Schocken M, Zhu X, Effros RB. Immune effects of hormone replacement therapy in post-menopausal women. Exp Gerontol (2001) 36:311-26. doi:10.1016/S0531-5565(00)00195-9

28. Sathaliyawala T, Kubota M, Yudanin N, Turner D, Camp P, Thome JJ, et al. Distribution and compartmentalization of human circulating and tissue-resident memory T cell subsets. Immunity (2013) 38(1):187-97. doi:10.1016/j. immuni.2012.09.020

29. Johannisson A, Festin R. Phenotype transition of CD4+ T cells from CD45RA to CD45R0 is accompanied by cell activation and proliferation. Cytometry (1995) 19(4):343-52. doi:10.1002/cyto.990190409

30. Marzio R, Mauël J, Betz-Corradin S. CD69 and regulation of the immune function. Immunopharmacol Immunotoxicol (1999) 21(3):565-82. doi:10.3109/08923979909007126 
31. Han Y, Guo Q, Zhang M, Chen Z, Cao X. CD69+ CD4+ CD25- T cells, a new subset of regulatory $\mathrm{T}$ cells, suppress $\mathrm{T}$ cell proliferation through membrane-bound TGF-beta 1. J Immunol (2009) 182(1):111-20. doi:10.4049/ jimmunol.182.1.111

32. Cortés JR, Sánchez-DíazR, BovolentaER, Barreiro O, Lasarte S, Matesanz-Marín A, et al. Maintenance of immune tolerance by Foxp3+ regulatory $\mathrm{T}$ cells requires CD69 expression. J Autoimmun (2014) 55:51-62. doi:10.1016/j.jaut.2014.05.007

33. Nakayama T, Kasprowicz DJ, Yamashita M, Schubert LA, Gillard G, Kimura M, et al. The generation of mature, single-positive thymocytes in vivo is dysregulated by CD69 blockade or overexpression. J Immunol (2001) 168(1):87-94. doi:10.4049/jimmunol.168.1.87

34. Brenchley JM, Douek DC, Ambrozak DR, Chatterji M, Betts MR, Davis LS, et al. Expansion of activated human naïve T-cells precedes effector function. Clin Exp Immunol (2002) 130(3):432-40. doi:10.1046/j.1365-2249.2002.02015.x

35. Grigorova IL, Panteleev M, Cyster JG. Lymph node cortical sinus organization and relationship to lymphocyte egress dynamics and antigen exposure. Proc Natl Acad Sci U S A (2010) 107(47):20447-52. doi:10.1073/pnas.1009968107

36. Schoenberger SP. CD 69 guides CD4+ T cells to the seat of memory. Proc Natl Acad Sci U S A (2012) 109(22):8358-9. doi:10.1073/pnas.1204616109

37. Pekalski ML, Ferreira RC, Coulson RM, Cutler AJ, Guo H, Smyth DJ, et al. Postthymic expansion in human CD4 naive T cells defined by expression of functional high-affinity IL-2 receptors. J Immunol (2013) 190(6):2554-66. doi:10.4049/jimmunol.1202914

38. Hoffmann P, Eder R, Boeld TJ, Doser K, Piseshka B, Andreesen R, et al. Only the CD45RA+ subpopulation of CD4+CD25high $\mathrm{T}$ cells gives rise to homogeneous regulatory T-cell lines upon in vitro expansion. Blood (2006) 108(13):4260-7. doi:10.1182/blood-2006-06-027409

39. Miyara M, Yoshioka Y, Kitoh A, Shima T, Wing K, Niwa A, et al. Functional delineation and differentiation dynamics of human CD4+ T cells expressing the FoxP3 transcription factor. Immunity (2009) 30(6):899-911. doi:10.1016/j. immuni.2009.03.019

40. Triplett TA, Curti BD, Bonafede PR, Miller WL, Walker EB, Weinberg AD. Defining a functionally distinct subset of human memory CD4+ T cells that are CD25POS and FOXP3NEG. Eur J Immunol (2012) 42(7):1893-905. doi:10.1002/eji.201242444

41. Gutsol AA, Sokhonevich NA, Kofanova KA, Litvinova LS. The effects of testosterone and $\beta$-estradiol on activation of lymphocytes associated with IL-2 production and expression of CD25 (IL-2R $\alpha$ ). Cell Tiss Biol (2014) 8(6):473-7. doi:10.1134/S1990519X14060030

42. Page ST, Plymate SR, Bremner WJ, Matsumoto AM, Hess DL, Lin DW, et al. Effect of medical castration on CD4+ CD25+ T cells, CD8+ T cell IFNgamma expression, and NK cells: a physiological role for testosterone and/ or its metabolites. Am J Physiol Endocrinol Metab (2006) 290(5):E856-63. doi:10.1152/ajpendo.00484.2005

43. McMurray RW, Suwannaroj S, Ndebele K, Jenkins JK. Differential effects of sex steroids on $\mathrm{T}$ and $\mathrm{B}$ cells: modulation of cell cycle phase distribution, apoptosis and bcl-2 protein levels. Pathobiology (2001) 69(1):44-58. doi: $10.1159 / 000048757$

44. Sprent J. Burnet oration. T-cell survival and the role of cytokines. Immunol Cell Biol (2001) 79(3):199-206. doi:10.1046/j.1440-1711.2001.00999.x
45. Kissick HT, Sanda MG, Dunn LK, Pellegrini KL, On ST, Noel JK, et al. Androgens alter T-cell immunity by inhibiting T-helper 1 differentiation. Proc Natl Acad Sci U S A (2014) 111(27):9887-92. doi:10.1073/pnas.1402468111

46. Walecki M, Eisel F, Klug J, Baal N, Paradowska-Dogan A, Wahle E, et al. Androgen receptor modulates Foxp3 expression in CD4+CD25+Foxp3+ regulatory T-cells. Mol Biol Cell (2015) 26(15):2845-57. doi:10.1091/mbc. E14-08-1323

47. Abdullah M, Chai PS, Loh CY, Chong MY, Quay HW, Vidyadaran S, et al. Carica papaya increases regulatory $\mathrm{T}$ cells and reduces IFN- $\gamma^{+} \mathrm{CD} 4^{+} \mathrm{T}$ cells in healthy human subjects. Mol Nutr Food Res (2011) 55:83-806. doi:10.1002/ mnfr.201100087

48. Boyman O, Sprent J. The role of interleukin-2 during homeostasis and activation of the immune system. Nat Rev Immunol (2012) 12:180-90. doi:10.1038/ nri3156

49. Li S, Xie Q, Zeng Y, Zou C, Liu X, Wu S, et al. A naturally occurring CD8(+) CD122(+) T-cell subset as a memory-like Treg family. Cell Mol Immunol (2014) 11(4):326-31. doi:10.1038/cmi.2014.25

50. Niu X, Huang Z, Zhang L, Ren X, Wang J. Auraptene has the inhibitory property on murine T lymphocyte activation. Eur J Pharmacol (2015) 750:8-13. doi:10.1016/j.ejphar.2015.01.017

51. Allegra M, Tesoriere L, D’Acquist F, Perretti M, Livrea MA. Inhibition of the TCR-mediated activation of naïve murine $\mathrm{T}$ cells by cactus pear fruit extracts Proc Physiol Soc (2007). Available from: http://www.physoc.org/proceedings/ abstract/Proc\%20Life\%20SciencesPC496

52. Guo W, Li P, Zhao G, Fan H, Hu Y, Hou Y. Glucocorticoid receptor mediates the effect of progesterone on uterine natural killer cells. Am J Reprod Immunol (2012) 67(6):463-73. doi:10.1111/j.1600-0897.2012.01114.x

53. Kiess W, Liu LL, Hall NR. Lymphocyte subset distribution and natural killer cell activity in men with idiopathic hypogonadotropic hypogonadism. Acta Endocrinol (Copenh) (1991) 124(4):399-404.

54. Craston R, Koh M, Mc Dermott A, Ray N, Prentice HG, Lowdell MW. Temporal dynamics of CD69 expression on lymphoid cells. J Immunol Methods (1997) 209(1):37-45. doi:10.1016/S0022-1759(97)00143-9

55. Abdullah M, Chau PS, Chong MY, Mohd Tohit ER, Ramasamy R, Chong PP, et al. Gender effect on in vivo lymphocyte subset levels of healthy individuals. Cell Immunol (2012) 272:214-9. doi:10.1016/j.cellimm.2011.10.009

56. Oertelt-Prigione $S$. The influence of sex and gender on the immune response Autoimmun Rev (2012) 11(6-7):A479-85. doi:10.1016/j.autrev.2011.11.022

Conflict of Interest Statement: The authors declare that the research was conducted in the absence of any commercial or financial relationships that could be construed as a potential conflict of interest.

Copyright (C) 2017 Jumat, Chong, Seman, Jamaluddin, Wong and Abdullah. This is an open-access article distributed under the terms of the Creative Commons Attribution License (CC BY). The use, distribution or reproduction in other forums is permitted, provided the original author(s) or licensor are credited and that the original publication in this journal is cited, in accordance with accepted academic practice. No use, distribution or reproduction is permitted which does not comply with these terms. 